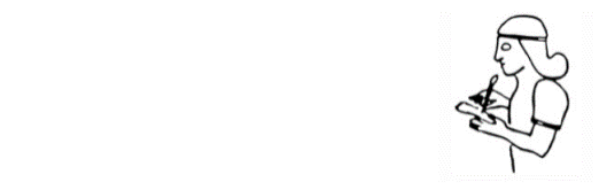

\begin{tabular}{|l|l|l|l|}
\hline ARCHIVUM ANATOLICUM (ArAn) & $14 / 1$ & 2020 & $83-94$ \\
\hline
\end{tabular}

\title{
KÖLE SEVKIYYATI HAKKINDA BİR KÜLTEPE METNİ
}

\author{
Hakan EROL * \\ ORCID:0000-0003-0089-1010
}

\section{Makale Bilgisi}

Başvuru: 06 Şubat 2020

Kabul: 30 Mayıs 2020

\section{Article Info}

Received: February 06, 2020

Accepted: May 30, 2020

$\ddot{O} z$

Kültepe kazılarının 1992 sezonunda Asurlu tüccarlar Elamma (arşivinin önemli bir kısmı 1991 yılında bulunmuştur), Kuliya ve Šuİštar'a ait arşivler ele geçmiştir. Burada tanıtılan köle sevki hakkındaki belge ile konuyla ilgisi bulunmayan diğer bir belge ise bu arşivlerin dışında, farklı açmalarda ortaya çıkarılmıştır. Makaleye konu olan köle nakliyle ilgili mektupta ismi verilmeyen bir kadın kölenin ve muhtemelen onun çocuklarının adı belirtilmeyen bir yerden Tegarama şehrine veya Hattum bölgesine sevk edilmesi istenmektedir. Ancak muhtemelen kölenin şahsiyla ilgili bir endişeden dolayı sevkiyatın kaçak yollardan yapılması ve ĕger güvenlik sıkı ve şartlar uygun değilse, köle için bir yıllık tahıl depolanarak sevkiyatın geciktirilmesi istenmektedir. Tanitılan diğer belge de bir mektuptur, fakat oldukça kötü korunmuştur. Mektubun konusu tam olarak anlaşılamamakla birlikte, Nanibatal adl bir şahisla mektubun yazarı Šalim-ahum arasındaki mesele ya da hesaplaşma ile ilgili olduğu söylenebilir.

* Doç. Dr., A. Ü. Dil ve Tarih-Coğrafya Fakültesi, Eskiçağ Dilleri ve Kültürleri Bölümü, Sumeroloji Anabilim Dal, herol@ankara.edu.tr 
Anahtar Kelimeler: Kültepe tabletleri, 1992 yılı kazlları, köle sevkiyatı, Tegarama, Hattum

\section{Abstract}

\section{A Kültepe Text about Slave Transportation}

In the 1992 excavation season of Kültepe three archives that belong to the Assyrian traders Elamma (the bulk of his archive was unearthed in 1991 season), Kuliya and Šu-Ištar were discovered. The tablet concerning slave transportation and an irrelevant another tablet fragment introduced in this article, discovered in the same year, however, were found in some different points away from these archives. The tablet, main subject of this article, is a letter about the slave transportation. An anonymous female slave and possible her children were wanted to be transferred to Tegarama or Hattum from an unnamed place. However, probably due to an apprehension regarding the personality of the slave, the transportation was wanted to be conducted via the smuggling road and if the guard or the security was tight and the situation was not convenient, the transportation was requested to be delayed by storing grain for one year, possibly for the subsistence of the slave. The other tablet introduced here for the first time is also a letter, but it is in a very bad condition to understand the content clearly. Although the subject of the letter is not very clear, one may assume that it is related to a problem or account between Šalimahum, the writer of the letter, and Nanibatal.

Keywords: Kültepe texts, 1992 excavation season, slave transportation, Tegarama, Hattum

\section{Giriş}

Bu yazıda tanıtılan Kt 92/k 1036 numaralı belge Kültepe kazılarının 1992 sezonunda bulunmuştur. Fakat bu tablet söz konusu kazı sezonunda ortaya çıkarılan, Asurlu tüccarlar Elamma, Kuliya ve Šu-Ǐstar'a ait büyük arşivlerin ele geçirildiği evlerde değil, Kültepe kazısı başkanı F. Kulakoğlu'ndan alınan bilgiye göre, farklı bir açmada ele geçmiştir. Ancak 1992 yılı kazı raporları henüz yayımlanmadığı için tabletin tam olarak hangi açmada ve ne şekilde bulunduğunu bilemiyoruz. Bu makalede ayrıca, 1992 yılı tabletleri içinden yayımlanmamış tablet kalmaması adına, muhtemelen kazı alanı temizliği sırasında ve tek başına bulunmuş, oldukça hasarlı durumdaki Kt 92/k 1035 numaralı başka bir tablet de tanıtılmaktadır. 
Kt 92/k 1036 envanter numaralı tablet Kura tarafindan Aššur-malik ve Dan-Aššur adlı tüccarlara ve Ab-šalim adlı bir kadına gönderilmiş mektuptur. Şahısların baba isimleri kayıtlı olmadığ 1 için kimlikleri tespit edilememektedir. Mektup, bir kadın kölenin ve bir çocuğun adı belirtilmeyen bir yerden Tegarama veya Hattum'a sevk edilmesi ile ilgilidir. ${ }^{1}$ Aslında köle sevkiyatı Kültepe belgelerinde çok nadir karşılaşılan bir durum değildir, fakat mektuptaki "elinizden geliyorsa ...., elinizden geldiği kadarınca; eğer güvenlik sıkı ise ve uygun değilse ..." gibi ifadeler, üstü kapalı bir şekilde, bu sevkiyatın yapılacağı bölgede olağan dışı bazı gelişmelerin yaşandığına işaret edebilir.

28 satırdan oluşan mektup, işaretlerin çok sık yazıldığı sol kenardaki son satır dışında oldukça anlaşılır durumdadır ve iyi korunmuştur. Metindeki bazı işaretlerin yanlış yazılmış olması belgenin yazarının usta bir kâtip olmadığına işaret edebilir. 1-888-92 Müze Envanter Numarasına sahip belge, açık devetüyü renginde ve $5.3 \times 4.5 \times 1.5 \mathrm{~cm}$ ölçülerindedir.

\section{Kt 92/k 1036}

\begin{tabular}{|c|c|c|}
\hline Ö.y. 1 & $a-n a$ A-šur-ma-lik & \\
\hline 2 & Dan-A-šur ú Áb-ša-lim & \\
\hline 3 & $q i_{-}-b i_{4}-m a$ um-ma Ku-ra-/ma & \\
\hline 4 & $a-h u-a: a-t \grave{u}-n u$ & \\
\hline 5 & šu-ma a-ma-kam & \\
\hline 6 & ta-le-e-a: am-tám! & ! met. tim) \\
\hline 7 & ú șú-ùh-ra-am & \\
\hline 8 & $m a-l a:$ ta-le-e-a-/ni & \\
\hline 9 & šu-ul!-ha-ni-im & !(met. qúl) \\
\hline 10 & $a$-di KÙ.BABBAR 10 GÍN & \\
\hline 11 & gus-um-ra-ma & \\
\hline
\end{tabular}

A.k. $12 \quad a-n a$ Té-ga-ra-ma

A.y. $13 \quad$ ' $\dot{u}^{?\urcorner}$ Ha-tim šé-bi-lá-/ni-/ši

14 šu-ma ma-șa-ra-tum

1 Eski Asur Ticaret Kolonileri Döneminde kölelik ile ilgili detaylı bilgi için bkz. Sebahattin Bayram ve Salih Çeçen, "Yeni Belgelerin Işs̆ğında Eski Anadolu'da Kölelik Müessesesi", Belleten C. LX, S. 229, (1996); Yusuf Kılıç ve Suzan Akkuş, "Çivi Yazılı Hukukta Köle Satış Bedelleri”, F.Ü. Orta Doğu Araştırmaları Dergisi, C.VI, S.2, (2010); Jacob Jan De Ridder, "Slaves in Kārum Kaneš", 9. Uluslararası Hititoloji Kongresi Bildirileri, I. Cilt, ed. Aygül Süel, Ankara, 2019. 


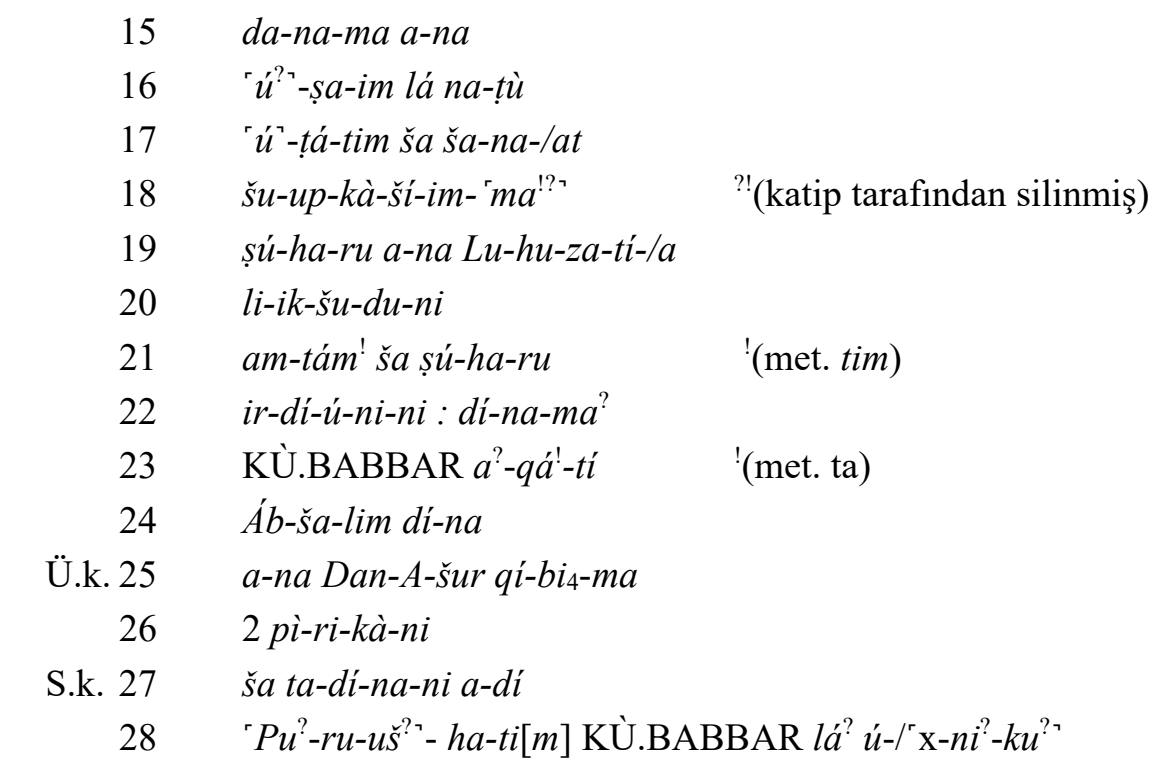

Tercüme: ${ }^{1-3)}$ Aššur-malik'e, Dan-Aššur'a ve Ab-šalim'e söyle! Kura şöyle (söyler): ${ }^{4-9)}$ Sizler kardeşlerimsiniz. Eğer orada yapabiliyorsanız, kadın köleyi ve çocuğu elinizden geldiğince (/imkânınız çerçevesinde) buraya sevk edin. ${ }^{10-13)} 10$ šeqel kadar gümüş harcayın ve onu Tegarama' ya ya da Hattum'a gönderin. ${ }^{14-18)}$ Eğer güvenlik sıkı ise ve çıkış için (durum) uygun değilse (bu) yılın tahılını onun için yığın. ${ }^{19-20)}$ Hizmetçiler Luhuzattiya'ya varsınlar. ${ }^{21-24)}$ Hizmetçilerin sevk ettiği kadın köleyi satın ve gümüşü Ab-šalim'in eline verin. ${ }^{25-28)}$ Dan-Aššur'a söyle! Bana verdiğin 2 (parça) pirikannum kumaşını Purušatum'a? kadar gümüş(e) [.........

\section{Açıklamalar:}

St. 7: șú-ùh-ra-am: Kolektif olarak "çocuklar" anlamında sadece Eski Asurca metinlerde geçen șuhrum terimi (CAD Ș, 236b) ile burada, kız ya da erkek fark etmeden kadın kölenin çocukları kast edilmiş olmalıdır.

St. 9: ̌̌u-ul'-ha-ni-im: šalāhum fiilinin "çıkarmak, geri almak, kurtarmak" ve "sevk etmek; göndermek" anlamları bulunmaktadır (CAD Š/I, 193b). Burada kelime, "kurtarmak" anlamını da içerecek şekilde "göndermek" karşılı̆̆ında kullanılmış olmalıdır. Fiil formunun sonunda ventif eki (-nim) kullanılmış olsa da kölenin sevk edileceği yer yazarın bulunduğu yer olmayabilir, çünkü kölenin belirli bir yere değil, alternatifli olarak, Tegarama'ya ya da Hattum'a sevk edilmesi istenmektedir.

St. 26: pì-ri-kà-ni: saptinnum cinsi kumaş ile birlikte pirikannum türü kumaşın oldukça ucuz bir Anadolu ürünü olduğu ve ticaretinin sadece 
Anadolu içinde yapıldı $\breve{g} 1$ bilinmektedir. VS 26, 9 numaralı metinden öğrendiğimize göre, Anadolu içinde bu pirikannum ve saptinnum cinsi kumaşların ticaretini yaptıkları için dönemin önde gelen tüccarlarından bazıları da dâhil olmak üzere birçok Asurlu tüccar Asur şehir meclisin aldığ 1 karar ile cezalandırılmıştır. Belgede Asur şehir meclisinin bu konudaki emirlerinin sert olduğu da belirtilmiştir. ${ }^{2}$ Asurlu yöneticiler, aldıkları bu kararla Asurlu tüccarların yerel tekstil ürünlerine zaman ve para harcamalarını engellemenin dışında, hem Asur'da üretilen hem de alım-satımından doğrudan veya vergilendirme yoluyla dolaylı olarak bizzat şehir meclisinin de kâr sağladığı, çevre bölgelerden Asur pazarına getirilen Mezopotamya kumaşlarının ticaretinin olumsuz etkilenmesini önlemek istemişlerdir. ${ }^{3}$

St. 28: 'Pu'-ru-ušs? $-h a-t i[m]$ KÙ.BABBAR lá ${ }^{?} \quad \dot{u}-/^{r} \mathrm{x}-n i^{?}-k u^{?\urcorner}$ : Tabletin bu son satırındaki işaretler çok sıkışık bir şekilde yazıldığından önerilen işaretlerin doğruluğu şüphelidir.

\section{Belgenin Yorumu:}

Aššur-malik ve Dan-Aššur dışında Ab-šalim adlı bir kadına hitaben Kura tarafından yazılmış mektubun nereden ve nereye gönderildiği bilinmemektedir. Her ne kadar belge Kaniš’te bulunmuş olsa da içeriğindeki ifadeler mektubun ilk adresinin burası olmadığına; bunun gönderilen asıl mektubun kopyası olduğuna işaret edebilir. Kura muhataplarına, eğer ellerinden geliyorsa, 10 šeqel gümüş masraf ederek, ismini belirtmediği bir kadın köleyi ${ }^{4}$ ve çocukları Tegarama ya da Hattum'a sevk etmelerini istemektedir. Tegarama'nın modern Gürün ile ilişkilendirilmek istenmesi ${ }^{5}$ ve Hattum'un, Kaniš' in doğusu ve kuzeyindeki bölgeye karşılık kullanılan bir coğrafi terim olarak değerlendirilmesi, ${ }^{6}$ söz konusu köle naklinin, Asur kervanlarının Fırat Nehrini geçtikleri merkez olan Hahhum'dan ya da bu merkeze yakın bir yerden yapıldığına işaret etmektedir. Çünkü mektubun yazarının "güvenliğin sıkı" ve "çıkışın uygun olmaması" durumunda kadın

2 Klaas R. Veenhof, Aspects of Old Assyrian Trade and its Terminologies; Leiden, Studia et Documenta, Volume X, Brill, 1972, s. 124-128

3 Mogens T. Larsen, Ancient Kanesh, A Merchant Colony in Bronze Age Anatolia, NewYork: Cambridge University Press, 2015, 118.

4 "Kadın köle" anlamındaki amtum teriminin Asurlu tüccarların Anadolu'da evlendikleri ikinci eşleri için de kullanıldığı bilinmektedir. Burada amtum "kadın köle" olarak bahsi geçen kişinin, Kura'nın ikinci eşi ve belki de mektubun alıcıları arasındaki Bayan Ab-šalim olması ihtimal dâhilindedir.

5 Gojko Barjamovic, A Historical Geography of Anatolia in the Old Assyrian Colony Period: Copenhagen, Carsten Niebuhr Institute Publications 38, 2011, 131.

6 RGTC 4, 57; Barjamovic, A Historical Geography, 164. 
köle için bir y1llık tahıl alınarak ${ }^{7}$ sevkiyatın geciktirilmesini istemesi, Hahhum şehrini geçtikten sonra Kaniš'e giden ana güzergâhtan ayrılarak kaçakçılık için kullanılan ve Turhumit'e çıkan tali yolun, yani harran sukunnim' in ${ }^{8}$ kullanılacağına işaret etmektedir. Zira Kaniš' in kuzeyinde aranan bir bakır üretim merkezi olan Turhumit'in Hattum bölgesindeki şehirlerden biri olduğu da iddia edilmektedir. ${ }^{9}$ Bununla birlikte söz konusu kadın kölenin ve çocuğun niçin Kaniš’e değil de büyük olasılıkla kaçak yoldan Hattum bölgesine sevk edilmek istendiği açık değildir. Çünkü bildiğimiz kadarıyla köle alımsatımından da vergi alındığına dair metinlerde herhangi bir kayıt bulunmamaktadır.

Kura, mektubunun devamında, hizmetçilerin (șuhārū) Luhuzattiya'ya ulaşmalarını ve onların beraberlerinde getirdikleri başka bir kadın kölenin satılarak parasının Ab-šalim adlı kadına verilmesini istemektedir. Adı geçen kadının kim olduğunu ve mektubun taraflarıyla ilişkisini bilemiyoruz. ${ }^{10}$ Yün ve deri ticareti konusunda önemli bir merkez olan Luhuzattiya ${ }^{11}$ şehrinin ise, Tegarama gibi, Hattum bölgesine giden yol üzerinde olduğu düşünülmektedir. ${ }^{12} \mathrm{Bu}$ durumda, hizmetçiler başka bir kadın köleyi Luhuzattiya'ya sevk edebiliyorken mektupta konu edilen kadın köleyi, bu şehre yakın bir yerde olduğu düşünülen Tegarama'ya niçin sevk edemedikleri sorusu akla gelmektedir. Belki de söz konusu endişe, kölenin vergilerden sakınmak için kaçak yoldan sevk edilmesinden değil, bizzat onun kimliğinden kaynaklanıyor olabilir.

Mektubunun sonunda Dan-A ššr'a hitap eden Kura, onun kendisine verdiği, Anadolu ürünü olduğunu bildiğimiz iki parça pirikannum kumaşı

7 Muhtemelen kadın kölenin geçimi için bir yıllık tahıl depolanması, mektubun yazarı Kura'nın, kadın kölenin bulunduğu şehirde bir evi olduğuna ve kölenin bu evde ikamet ettiğine işaret etmektedir.

8 Larsen, Ancient Kanesh, 135, 158.

9 Barjamovic, A Historical Geography, 164.

10 Ab-šalim ismi ATHE 24/A: 6, B: 12'de Amur-İštar'ın kızı; I, 584: 15'te Aššur-rēṣi'nin kızı; AKT 8, 300: 20, 22'de Ali-ahum'un karısı ve ICK 2, 156: 5'te Aššur-lamassī'nin kız kardeşi olarak kayıtlıdır. AKT 6-d, 348: 28-29'da Ab-šalim'in ve mektubun diğer alıcılarından, Dan-Aššur'un ortaklaşa bakırları olduğu kayıtlıdır.

11 İrfan Albayrak, "The Toponym Balīhum in the Kültepe Texts", Altorientalische Forschungen 35/1, (2008): 29, 31; Barjamovic A Historical Geography, 142.

12 Barjamovic, A Historical Geography, 158. Genellikle modern Elbistan civarında aranan ve sonraki Hitit Döneminde daha çok Lu(hu)wasantiya ve Yeni Asur Döneminde Lusanda yazılışıyla karşılaşılan Luhuzattiya kenti hakkında detaylı bilgi için bkz. Barjamovic $A$ Historical Geography, 133-142; Turgut Yiğit, "Eski Anadolu Kentlerinden Luhuzatia / Lawazantiya'nın Tarihi ve Lokalizasyonu Üzerine", Belleten LXI, (1997): 1-14; Tolga Pelvanoğlu, " $\mathrm{La}(\mathrm{Hu})$ Wazantiya: Ticari ve Dini Bir Merkezin Tarihçesi ve Lokalizasyonu", Archivum Anatolicum 13/2, (2019): 145-172. 
hakkında bilgi ya da talimat vermektedir. Ancak belgenin son satırındaki işaretler çok sıkışık şekilde yazıldığ için bu bilgi ya da talimatın ne olduğu okunamamaktadır.

$\mathrm{Bu}$ makalede tanıttığımız diğer belge oldukça hasarlı durumda ele geçmiştir ve 1992 yılı kazılarında bulunan ana arşivlerin dışında, farklı bir açmada bulunmuştur. Tabletin özellikle alt kenarı ve arka yüzünün büyük bir kısmı kırık durumdadır, bu nedenle içeriği tam olarak anlaşılamamaktadır. 1-

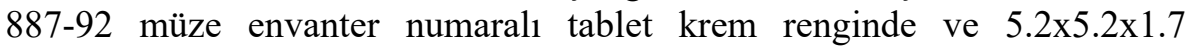
ölçülerindendir.

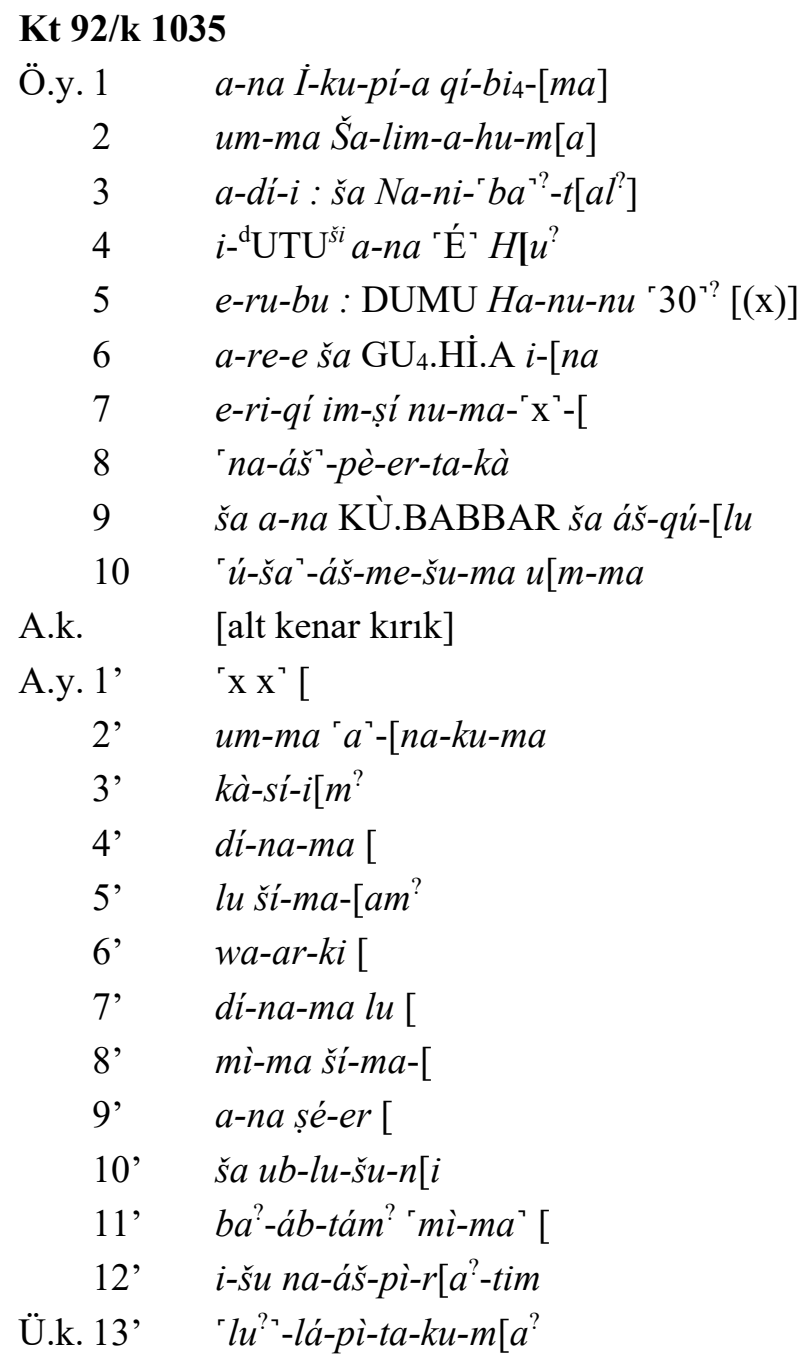


14' KÙ.BABBAR $l i-i \check{s}-q u \dot{u}-l u-{ }^{2} k u^{?}-m a^{? ?}[(\mathrm{x})$

S.k. 15, ú a-na-ku ha-ra-ni a-lá-a[k-ma

16' iš-tí-šu $a-z a-k u$

Tercüme: ${ }^{1-2)}$ İkūn-pīya'ya söyle! Šalim-ahhum şöyle (söyler): ${ }^{3-7)}$ Nanibatal hakkında; H[u....]'nın evine girdiğim gün ... Hanunu'nun oğlu arabalardaki 30 parça sı̆̆ır derisinden sorumludur. Tazmin [edeceğiz]. ${ }^{7-10)}$ Benim ödediğim gümüss ile ilgili senin belgeni ona duyurdum ve [o] şöyle $[\text { dedi: ............... }]^{\left.1 '-12^{\prime}\right)}[\ldots \ldots \ldots$ Ben] şöyle dedim: $[\ldots]$ kase $[\ldots .$.$] bana ver$ ve $[\ldots . .$.$] Ister bedeli [\ldots .$.$] sonra [\ldots .$.$] bana ver ve ister [\ldots]$ ticari malı $[\ldots .$.$] 'nın üzerine [\ldots]$ ona taşıdı̆̆ $1(\mathrm{~m})[\ldots .$.$] alacağı bütün [\ldots .$.$] mevcuttur.$ Belgeleri senin için kaydedeyim ki gümüşü sana ödesinler ve ben yoluma gideceğim [ve] onunla (hesabımı) temizleyeceğim.

\section{Açıklamalar:}

St. 3: $N a-n i-{ }^{-} b a^{? ?}-t\left[a l^{?}\right]$ : Eski Asurca metinlerde Nanibatal ismi bildiğimiz kadarıyla beş yerde kayıtlıdır: PRAG I, 753: 4; Kt m/k 144: 16 (yayımlanmamış); Kt 87/k 146: 2 (yayımlanmamış); Kt 87/k 546: 1 (yayımlanmamış) ve Kt 88/k 963: 3. Bu beş belgede kayıtlı Nanibatal adı muhtemelen tek bir kişiye işaret etmemektedir. Bu isimdeki bir şahıs, Kaniš kārumunun elçilerine gönderdiği mektup Kt 88/k 963: 3'te kārumun elçilerinden birisi olarak kayıtlıdır. ${ }^{13}$

St. 6: $a-r e-e ~ s ̌ a ~ \mathrm{GU}_{4}$.Hİ.A: Bir düzine kadar Kültepe metninde kayıtlı $\bar{a} r u$ terimine CAD A/II, 418a'da şüpheli olarak "post/deri" anlamı verilmiş ve kelimenin sadece Eski Asurca metinlerde geçtiği vurgulanmıștır. Metnimizde olduğu gibi, bu terim sadece üç belgede "sığır" (a. ša alpim/GU “sı̆ğı derisi") olarak kaydedilmiş, başka hiçbir hayvan ile ilişkilendirilmemiştir. āru terimi sadece TPAK 1, 69: 1'de "yüksek kalite" sıfatı ile nitelendirilmiştir: 2 a-re-e-

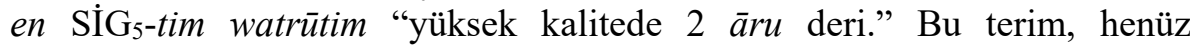
yayımlanmamış Kt 87/k 482: 15 'te ise Kültepe belgelerinde daha sık geçen maškum "deri" kelimesiyle birlikte yazılmıştır: $[\mathrm{x}+] 2$ maš-ku 3 a-ru " $[\mathrm{x}+] 2$ mašku derisi, 3 arru derisi." Dolayısıyla, bu iki deri türü arasında, elde edildikleri hayvan bakımından bir fark söz konusu olduğu ve $\bar{a} r u$ teriminin sığırdan elde edilen deriye işaret ettiği düşünülebilir.

13 Nanibatal hakkında detaylı bilgi için ayrıca bkz. İrfan Albayrak, "Kaniš Kārum’unun Bir Mektubu", Archivum Anatolicum 6, (2003): 5. 
St. 7: e-ri-qi: Genellikle, bakır, kalay, kumaşlar, yün, tahıl ve odun gibi hacimli malların nakliyesinde kullanılan yük arabalarının (eriqqum $)^{14}$ deri nakliyesinde de kullanıldığı anlaşılmaktadır.

\section{Belgenin Yorumu:}

Belge Šalim-ahum tarafından İkūn-pīya'ya gönderilmiş bir mektuptur. Her iki isim de Kültepe metinlerinde oldukça yaygındır, dolayısıyla baba adları verilmediği için şahısların kimlikleri bilinememektedir. Mektubun, bildiğimiz kadarıyla sadece beş farklı Kültepe metninde kayıtlı Nanibatal adlı bir Asurlu ile ilgili olduğu anlaşılmaktadır. Belgedeki ifadelere göre, ismi okunamayan bir şahsın evine girilmiş ve Hanunu adlı bir şahsın oğlunun (belki de Nanibatal) arabalara yüklenmiş 30 parça kadar sığır derisinden sorumlu olduğu belirtilmiştir. Mektubun geri kalan kısımları çok hasarlıdır ve anlamlı bir konu bütünlüğü sağlanamamaktadır. Ancak mektubun yazarı Šalim-ahum'un muhtemel Nanibatal ile arasındaki bir mesele ya da hesaplaşma ile ilgili gelişmeler hakkında muhatabı İkūn-pīya'ya bilgi verdiği görülmektedir.

\section{KAYNAKÇA}

Albayrak, İ., “Kaniš Kārum'unun Bir Mektubu”, Archivum Anatolicum 6, (2003): 1-9. Albayrak, İ., "The Toponym Balīhum in the Kültepe Texts", Altorientalische Forschungen 35/1, (2008): 28-35.

Barjamovic, G., A Historical Geography of Anatolia in the Old Assyrian Colony Period (CNIP 38), Copenhagen, 2011.

Bayram, S. - Çeçen, S. "Yeni Belgelerin Işı̆̆ında Eski Anadolu'da Kölelik Müessesesi”, Belleten C. LX, S. 229, (1996): 579-604.

De Ridder, J. J. "Slaves in Kārum Kaneš”, IX. Uluslararası Hititoloji Kongresi Bildirileri, I. Cilt, ed. Aygül Süel, Ankara, 2019: 203-210.

Dercksen, J. G., Old Assyrian Copper Trade in Anatolia, PIHANS 75, Leiden/İstanbul: 1996.

Gökçek, L. G. "The Use of Wagons (eriqqum) in Ancient Anatolia According to Texts from Kültepe", Zeitschrift für Assyriologie 96, (2006): 185-199.

Kılıç, Y.- Akkuş, S. "Çivi Yazılı Hukukta Köle Satış Bedelleri”, F.Ü. Orta Doğu Araştırmaları Dergisi, C.VI, S.2, (2010): 163-187.

Larsen, M. T., Ancient Kanesh, A Merchant Colony in Bronze Age Anatolia, Cambridge University Press, NewYork: 2015.

14 Kültepe metinlerinde yük arabalarının kullanımı hakkında detaylı bilgi için bkz. Jan G. Dercksen, Old Assyrian Copper Trade in Anatolia, PIHANS 75, Leiden/İstanbul: 1996, 6467; L. Gürkan Gökçek, "The Use of Wagons (eriqqum) in Ancient Anatolia According to Texts from Kültepe”, Zeitschrift für Assyriologie 96, (2006): 185-199. 
Pelvanoğlu, T., "La(Hu)Wazantiya: Ticari ve Dini Bir Merkezin Tarihçesi ve Lokalizasyonu", Archivum Anatolicum 13/2, (2019): 145-172.

Yiğit, T., "Eski Anadolu Kentlerinden Luhuzatia / Lawazantiya'nın Tarihi ve Lokalizasyonu Üzerine", Belleten LXI, (1997): 1-14.

Veenhof, K. R., Aspects of Old Assyrian Trade and its Terminologies; Studia et Documenta, Volume X, Brill, Leiden, 1972.

\section{KISALTMALAR}

AKT 6d Larsen, M. T., Kültepe Tabletleri 6-d, The Archive of the ŠalimAššur Family, Vol. 4, Texts Concerning Non-Family Members, Türk Tarih Kurumu Yayınları, Ankara: 2018.

AKT 8 Veenhof, K. R., Kültepe Tabletleri VIII, The Archive of Elamma, Son of Iddin-Suen, and his Family (Kt 91/k 285-568 and Kt 92/k 94187), Türk Tarih Kurumu Yayınları, Ankara: 2017.

ATHE Kienast, B., Die altassyrischen Texte des orientalischen Seminars der Universität Heidelberg und der Sammlung Erlenmeyer, Walter de Gruyter \& Co., Berlin: 1960.

CAD Chicago Assyrian Dictionary

PRAG I Hecker K., Kryszat G., ve Matouš, L., Kappadokische Keilschrifttafeln aus den Sammlungen der Karlsuniversität Prag I-II., Prag: 1998.

ICK 2 Matouš, L., Inscriptions cunéiformes de Kültepe, vol. 2, Prag: 1962.

RGTC 4 Kh. Nashef, Die Orts-und Gewasserbaneb der altassyrischen Zeit, Dr. Ludwig Reichert Verlag, Wiesbaden: 1992.

TPAK 1 Michel, C. ve Garelli, P., Tablettes paléo-assyriennes de Kültepe I, Institut Français D'etudes Anatoliennes Georges Dumezil İstanbul, Paris: 1997.

VS 26 Veenhof, K. R. ve Klengel-Brand, E., Altassyrische Tontafeln aus Kültepe. Texte und Siegelabrollungen, Vorderasiatische Schriftdenkmaler der Staatlischen Musen zu Berlin, Heft 26, Gebr. Mann Verlag, Berlin: 1992.

\section{Kt 92/k 1036}




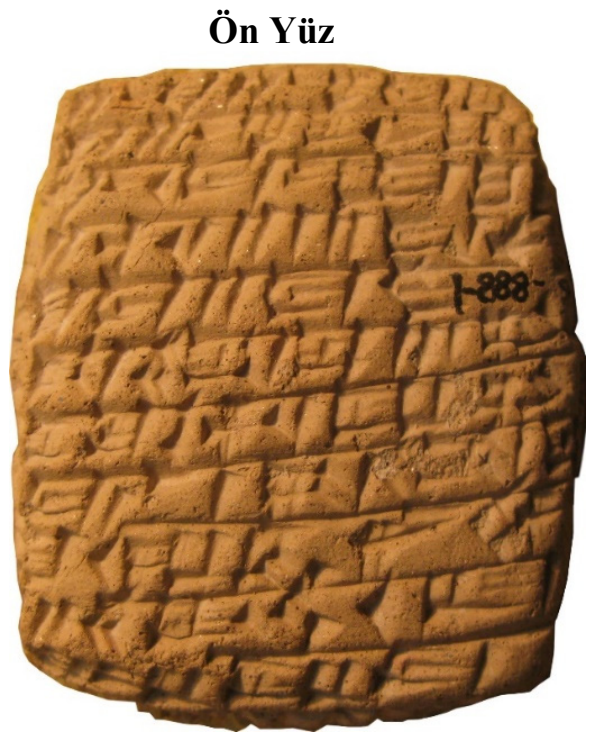

Alt Kenar

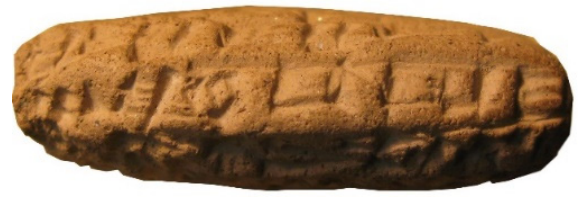

Arka Yüz

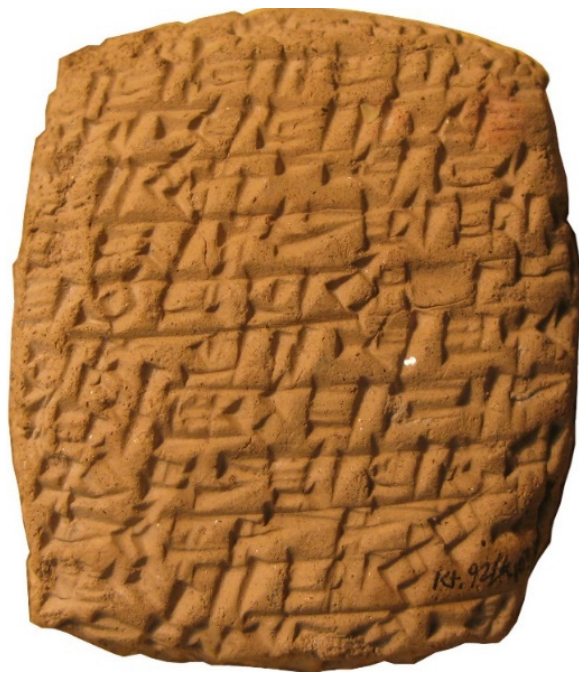

Üst Kenar

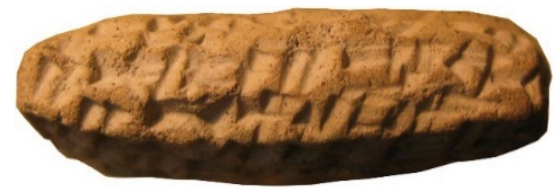

Sol Kenar

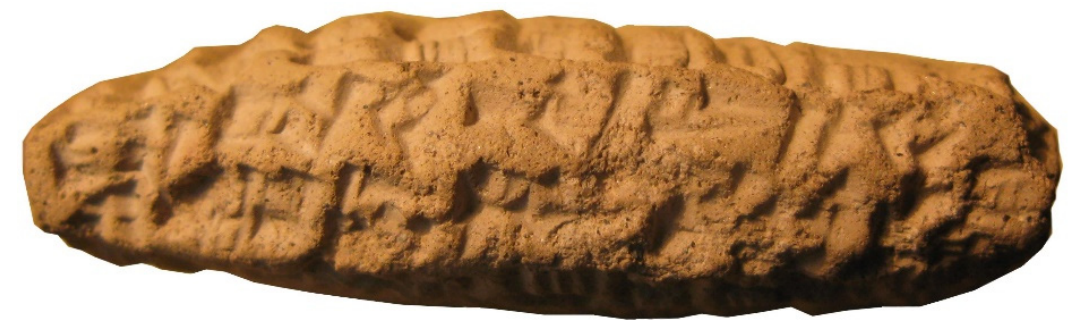

Kt 92/k 1035 
KÖLE SEVKIYYATI HAKKINDA BİR KÜLTEPE METNİ
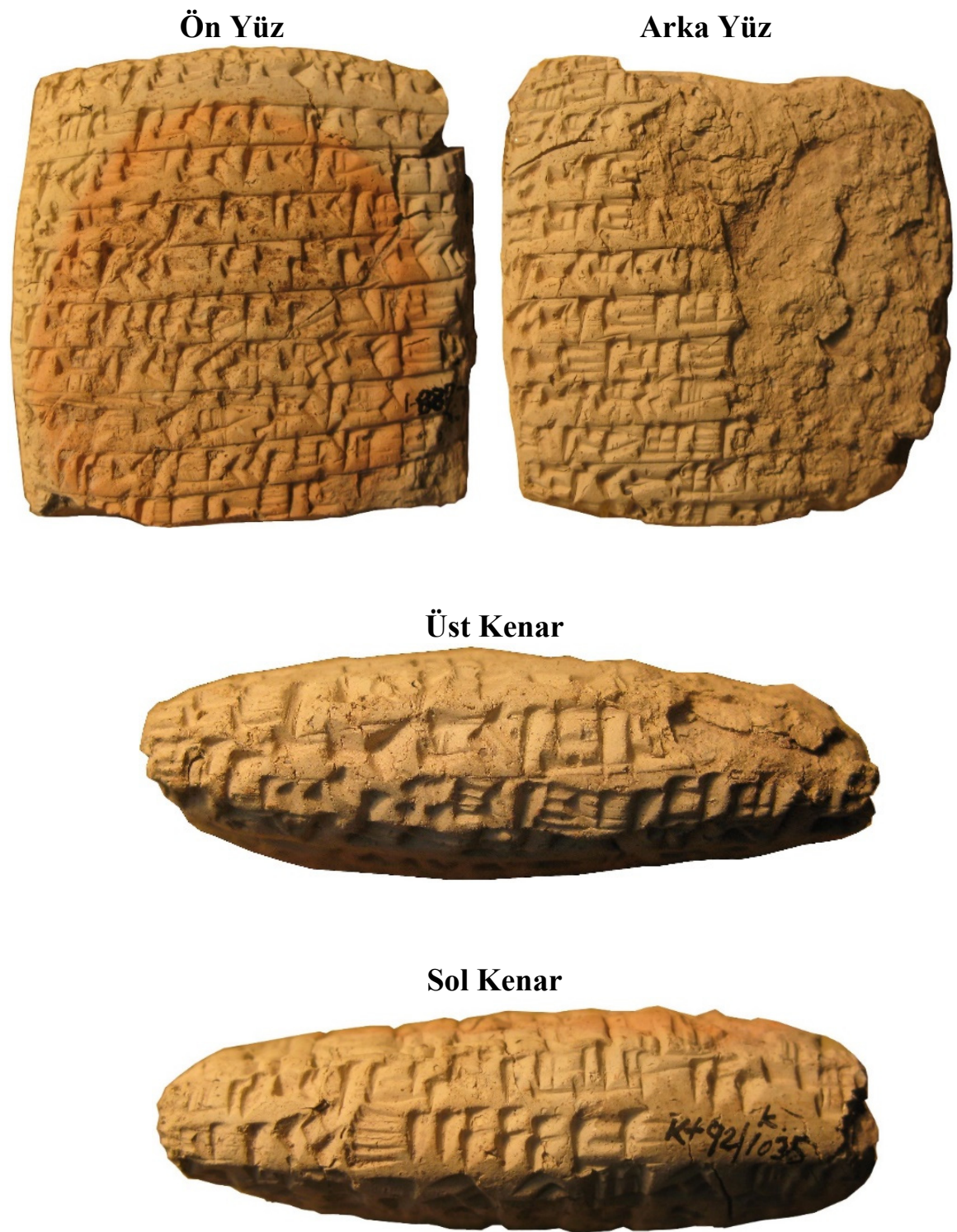